\title{
Accumulated effects of chronic, acute and man-induced erosion in Nørlev strand on the Danish west coast
}

\author{
Ofelia Yocasta Rivero ${ }^{1} \cdot$ Lucia Margheritini $^{1}$ (D) $\cdot$ Peter Frigaard $^{1}$ \\ Received: 8 July 2019 /Revised: 11 January 2021 / Accepted: 12 January 2021 / Published online: 4 February 2021 \\ (C) The Author(s) 2021
}

\begin{abstract}
This paper provides an in-depth analysis of the erosion at Nørlev Strand located on the Danish west coast. This location suffers from severe erosion; the result of a combined chronic, acute and, at least partially, man-induced erosion. The analysis is done by studying the average climatic conditions in the vicinity, and the effects of storms. Analysis shows an increase in the measured moderate to large wave events and consequent connection of the erosion problem to climate change. Other effects of climate change such as increase in rainfall were also considered and a surprisingly good correlation was found between coastal erosion in Nørlev and national storm records. Furthermore, a shift in mean wave direction has also been noted in the case of waves coming from the north. The significance that these changes can have in the sediment is assessed quantitatively through numerical modelling.
\end{abstract}

Keywords Chronic Erosion $\cdot$ Acute Erosion $\cdot$ Longshore sediment transport $\cdot$ Climate change $\cdot$ Storm events $\cdot$ Numerical model

\section{Introduction}

Major coastal erosion represents a management challenge for engineers and interested authorities. The understanding of the mechanisms regulating the erosion advancement and its causes are essential to predicting future development and adequate mitigation measures to protect both nature and private properties, and to deciding on the right investment for the purpose. In broad terms, coastal erosion is the consequence of a combination of two forms of erosion: chronic and acute erosion. Chronic erosion occurs on a regular basis and is the result of waves lifting the sediment and a long-shore current (also generated by the angle of attack of the waves) carrying it away. Summer and winter beach profiles may vary significantly, as we may assist to deposition in summer and erosion in winter, but when the net removal exceeds the net deposition for a long period of time, a beach is said to suffer from chronic erosion. Acute erosion usually happens during storms and generates a sediment transport from the inner to the outer profile. In this situation, the combination of wind, water level and waves drags the material from onshore to offshore. The amount of material is determined, among other things, by

Lucia Margheritini

mluc@build.aau.dk; build@build.aau.dk

1 Department Of The Built Environment, Aalborg University, Thomas Manns Vej 23, 9220 Aalborg Ø, Denmark wave height, direction and grain size. Other factors can influence the rate of erosion: hard (passive) protection measures such as groins, seawalls, breakwaters transfer the erosion to neighbouring stretches by interfering with the longshore current; increase in storm events such as in connection to climate change anomalies may also increase erosion by changing the wave attack angle to the coast or simply by providing more energy to the sediment transport.

The main objective of this work is to identify the main parameters affecting the erosion at Nørlev Strand on the Danish west coast. To do so, we use two complementary approaches: a historical analysis of wave heights, periods and directions and a comparison with profiles of erosion. The quantification of the erosion is based on numerical simulation at varying parameters and the identification of the most influencing parameter at our location. Finally, by using the long-time records (1981-2011) of storm events and climate change effects in Denmark obtained from the DHI (Danish Hydraulic Institute) records, we make some additional considerations on the costal erosion that may introduce a new parameter to be considered in future studies.

\section{Area of study}

Nørlev Strand is a $2.5 \mathrm{~km}$ coastal stretch occupied by summer cottages. It is located at the north-west coast of Denmark, bordering on the North Sea (Fig. 1). 
Fig. 1 Nørlev Strand is located north-west from the city of Hjørring and south-west from the port of Hirtshals. Nørlev Strand is part of the Danish north-west coast

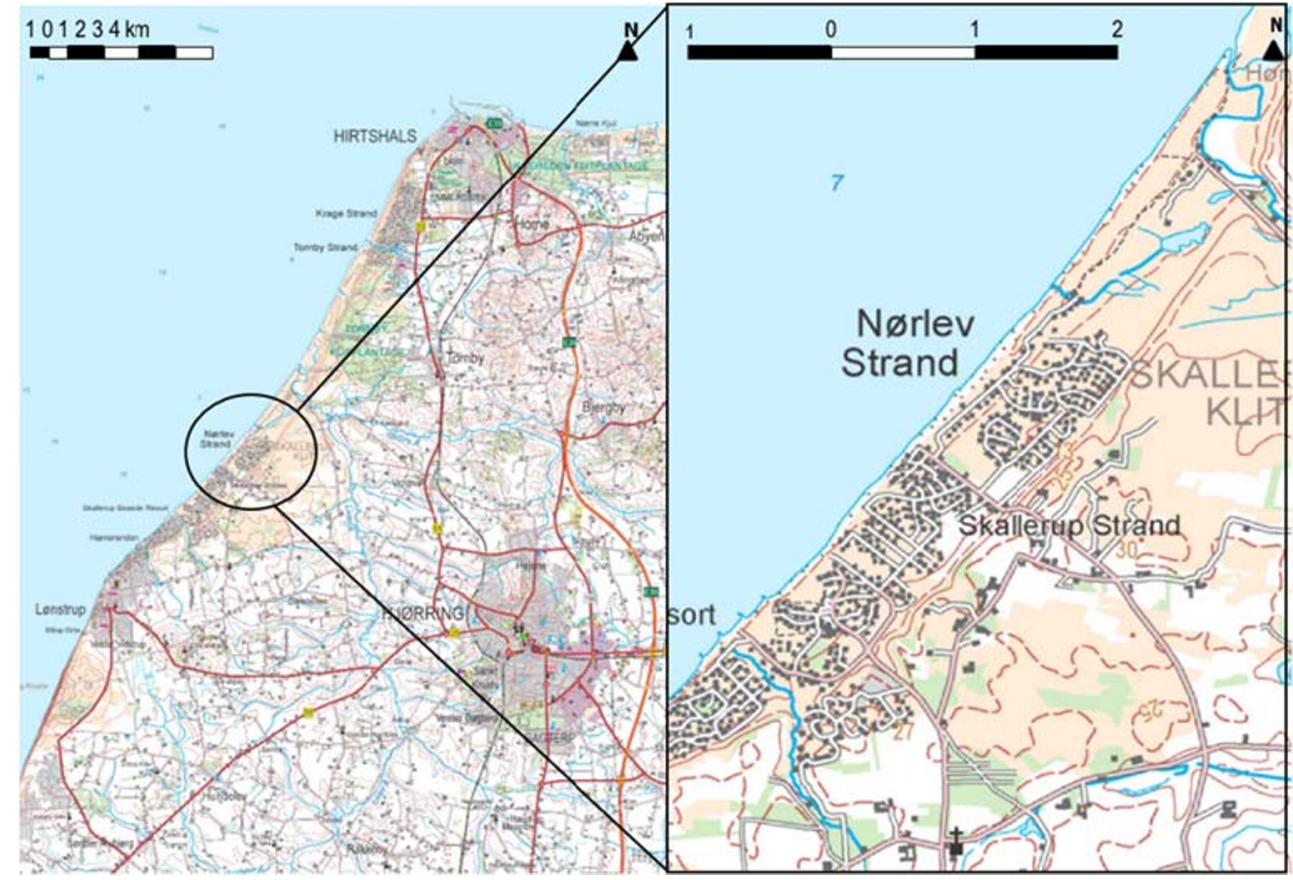

Nørlev Strand is a barred-beach with sandy dunes of heights varying between $6 \mathrm{~m}$ and $12 \mathrm{~m}$. While the beach is normally steeper towards the south, the shore face is steeper towards the north. The general trend is for the coastal transects to become steeper with time, and for the dunes to reduce in height. The theoretical depth of closure is estimated to be between $6.2 \mathrm{~m}$ for summer events and $8 \mathrm{~m}$ for winter events (Baptista et al. 2014) (Dean 2003). Despite this, beach profiles show large temporal variation passed the depth of closure. Dunes and beach fronts are composed mainly by non-cohesive materials such as gravel and sand, deposited during the Yoldia Sea period. Both materials are unconsolidated, thus becoming a material easily erodible. Most of the area is covered by a layer of aeolian sand, which is also easily transported by the wind (GEUS 2017). According to Saye and Pye 2006, the mean sediment size, $\mathrm{D}_{50}$, of the sand in the area is $0.233 \mathrm{~mm}$. There are recordings of intense erosive activity at Nørlev Strand. In December 2015 a powerful storm lead to the destruction of several summer houses located in Morgenvej street. Before this storm, no nourishments had been performed and no hard structures had been installed at Nørlev Strand. However, there are four groins south from the beach of the beach, at Skallerup Klit. Those were built in 1981 to protect the drainage system of the Skallerup Resort. This drainage system is no longer in use, but the groins were never removed. Since there is a consistent northward current along the north coast, it is downstream of the groins where the largest erosion can be found at Nørlev Strand. It is also at this location where Morgenvej is situated. The landowner's response to the 2015 storm was to point at the groins built upstream of Nørlev Strand as being allegedly increasing chronic erosion and, therefore, leaving the houses further exposed during storms (Fig. 2).

In Fig. 3, it is marked the location of Morgenvej. Cottages originally built far from the beach are now located atop of the dunes due to progressive erosion. The stretch is being
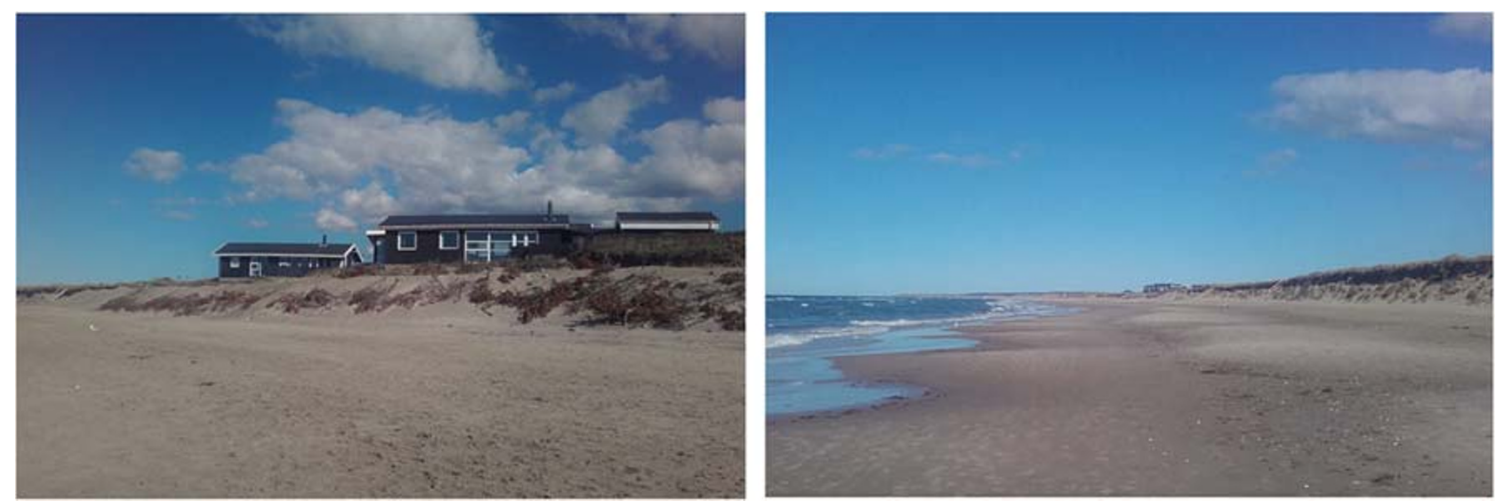

Fig. 2 Nørlev Strand. 2nd September 2016. Left: houses in Morgenvej. The dune in front of the houses was nourished after 2015 storm. Right: panoramic view of Nørlev Strand 
Fig. 3 Transects in Nørlev Strand and location of Morgenvej. The profile number increases from north to south; 1650 being the closest profile to the groins of Skallerup Resort

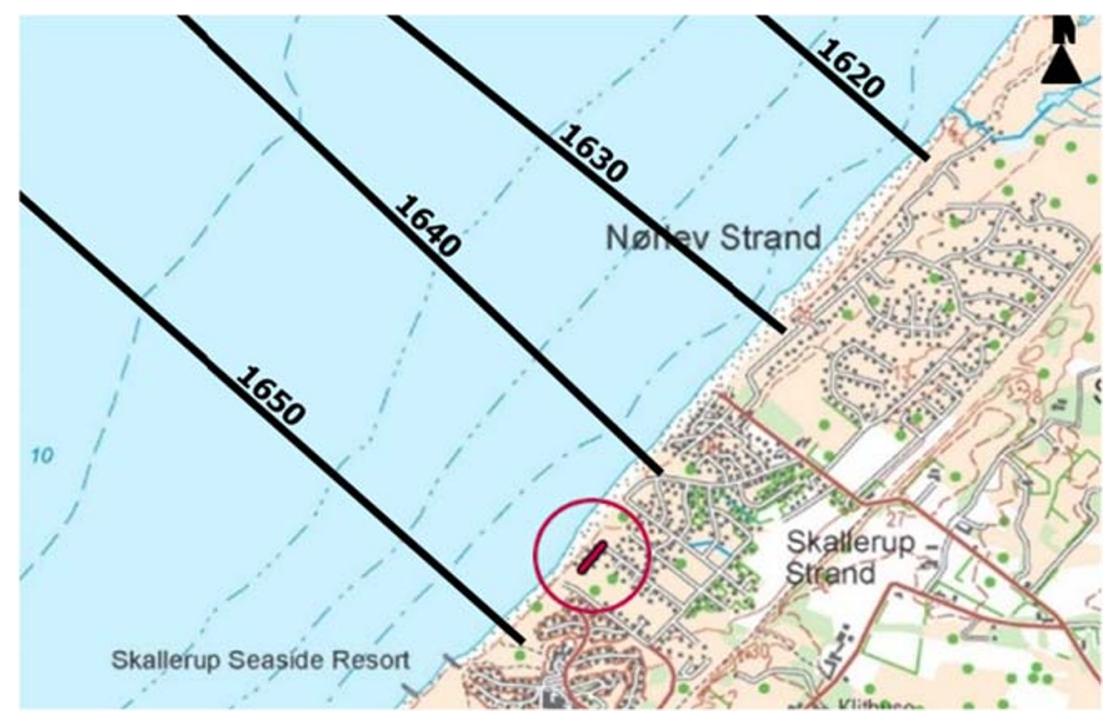

monitored with four profiles spaced $1 \mathrm{~km}$ from each other. Profiles 1650 and 1640 enclose Morgenvej. Comparing the evolution of these profiles with transects 1630 and 1620 gives an idea of the rapid evolution of the coastal retreat in front of Morgenvej. In Fig. 4, we have the available profile envelopes at Nørlev Strand for the four transects, from 1973 to 2016. There is retreat along the entire coastal stretch. This is quantified by obtaining the position of the coastal profiles at three heights: $0 \mathrm{~m}$ height (coastline), $1 \mathrm{~m}$ height and $4 \mathrm{~m}$ height (see also Fig. 10, "Climate Change" section).
From 1973 to 2016, profiles 1620 and 1630 have retreated at an average rate of $0.7 \mathrm{~m} /$ year and $0.6 \mathrm{~m} /$ year, respectively. The largest retreat rates per year are found at $1 \mathrm{~m}$ height in between 1985 and 1987, which equals $-10.2 \mathrm{~m} /$ year in profile 1620 and $-12.3 \mathrm{~m} /$ year, in profile 1630. At the coastline, the largest retreat was found in the period 1991 to 1993 , when profile 1620 retreated at an annual rate of $9.7 \mathrm{~m} /$ year and between 2000 and 2003 when profile 1630 retreated at an annual rate of $6.0 \mathrm{~m} /$ year at the coastline.
Fig. 4 Profile envelopes in Nørlev Strand. Top left: profile 1620. Top right: profile 1630. Bottom left: profile 1640. Bottom right: profile 1650
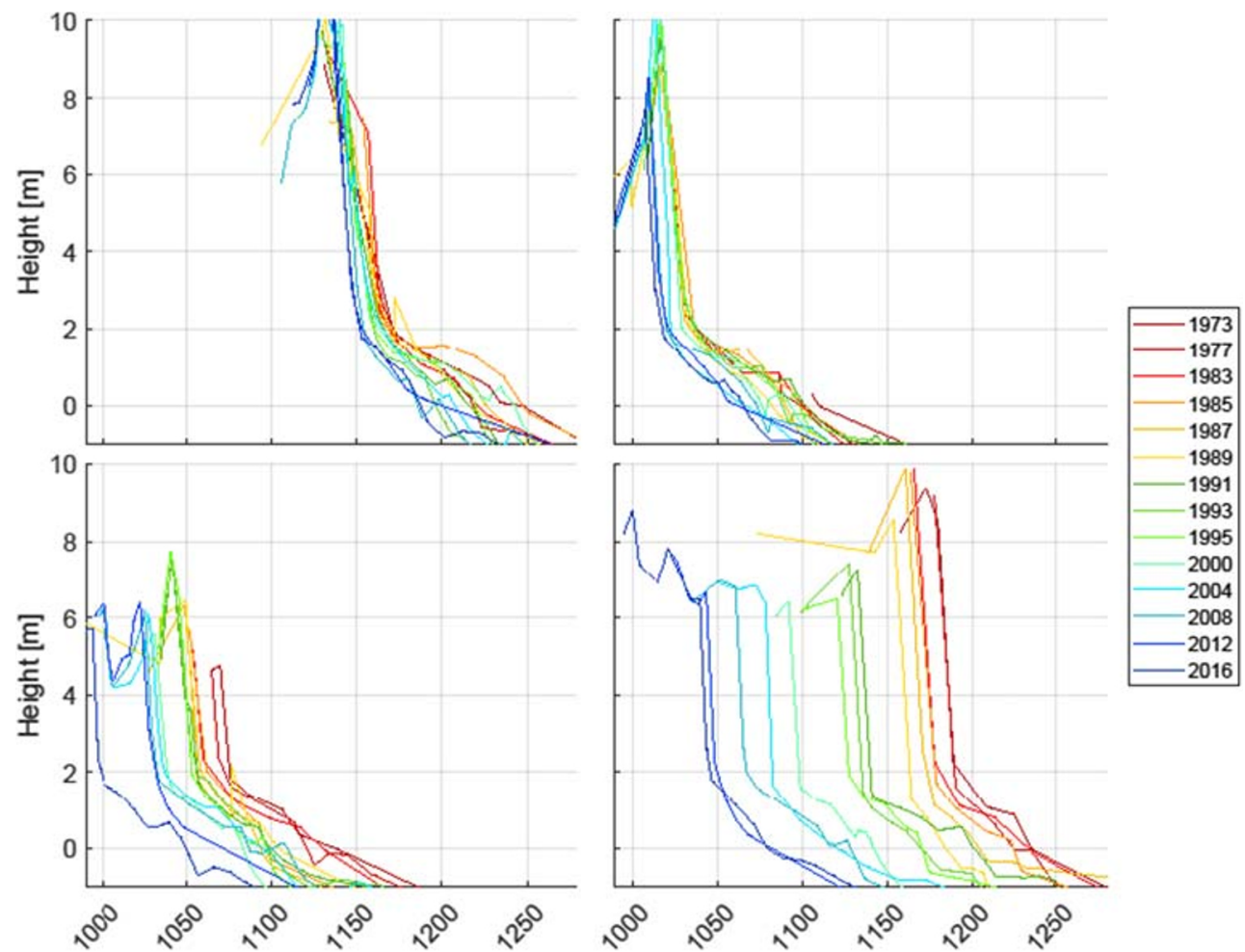
From 1973 to 2006 , profile 1640 erodes at a rate of about $1.9 \mathrm{~m}$ per year. In the period 1983 to 1985 , it happened the largest retreat at the coastline which was $15.9 \mathrm{~m} /$ year. At $1 \mathrm{~m}$ height, the largest retreat is found between 1977 and 1978 which equals to $-11 \mathrm{~m} /$ year. At $4 \mathrm{~m}$ height, the largest annual retreat happened between 2012 and 2016, equalling $7.5 \mathrm{~m} /$ year.

The erosion rate of profile 1650 from 1973 to 2016 has been $3.4 \mathrm{~m} /$ year, being the largest of the stretch. It is wellknown that the lee side erosion appears downstream of groins. However, at the coastline, the annual erosion rate of profile 1650 has been largest between 1991 and 1993 reaching $-15.7 \mathrm{~m} /$ year. Between 1977 and 1978, at a height of $1 \mathrm{~m}$, the profile retreated $14.7 \mathrm{~m}$. From 1991 to 1993 , the profile at a height of $4 \mathrm{~m}$ retreats at $11.1 \mathrm{~m} /$ year. If the total retreat from 1973 to 2016 is regarded, profile 1630 erodes the least: only $27 \mathrm{~m}$. It is followed by profile 1620 , with a total retreat of $30 \mathrm{~m}$. Profile 1640 erodes $81 \mathrm{~m}$.

Finally, profile 1650 retreats $147 \mathrm{~m}$., clearly being the less resilient part of the coastal stretch. Profiles 1620 and 1630 display the largest annual erosion rates between 2000 and 2008. Profile 1640 worsens gradually in time; the worst period being 2008 to 2016. At last, profile 1650, closer to the groins, suffers the largest erosion rates 10 years after the groins placement, from 1991 to 2000.

Figure 5 shows the wave roses of summer and winter. Besides the predominant western direction, the other two wave directions stand out. Sector $\left[250^{\circ}-295^{\circ}\right]$ agglutinates more than $60 \%$ of the incoming waves. Almost another $15 \%$ of the incoming waves are represented in sector $\left[340^{\circ}-25^{\circ}\right.$. Finally, $10 \%$ of the waves come from the sector $\left[25^{\circ}-70^{\circ}\right]$. Nevertheless, this third group is not relevant at Nørlev Strand. Due to its relative position in relation to Hirtshals port, the beach is sheltered from north-east waves. The average significant wave height is $1.14 \mathrm{~m}$, the modal wave direction is $272^{\circ}$ and the average peak period is $6.21 \mathrm{~s}$. The standard deviation of the average peak period is small, $2.24 \mathrm{~s}$, which suggests small variability during the analysis period. Indeed, most of the waves come from the west where the fetches are the largest, pointing to a large predominance of swell waves. On the other hand, the standard deviation of the average significant wave height is quite large in comparison, $0.76 \mathrm{~m}$.

\section{Methodology}

The study is divided in two parts:

1. One part uses the historical wind and wave data and profile measurements in order to relate measured erosion to significant events.

2. The second part uses a numerical model to quantify the erosion when varying the significant parameters affecting it.

For both parts, the following subsections explains in detail the data and relative analysis..

\section{Data}

Wave data is obtained from buoy 1041 located in the western offshore waters of Hirtshals port. It is located at $26 \mathrm{~km}$ west from Nørlev Strand, and at $17.5 \mathrm{~m}$ depth it is the closest source of data in the area. The UTM coordinates of the buoy are [536,702, 6,374,866]. It contains data from August 1999 to August 2012, but only 11 years of data are fully recorded. The study period is established based on this data. The measurements from the buoy are not directly manipulated, and the 3-h average of the different wave parameters are calculated. The used parameters are significant wave height, $H_{m 0}$, peak wave period $T_{p}$ and mean wave direction, $\theta_{m}$. The wave data needs to be treated for outliers and missing values. Additionally, another set of data is used, which corresponds to a wave buoy located closer to Hirtshals port, buoy 1012. It contains data from before February 1996 to today. This buoy is about $15 \mathrm{~km}$
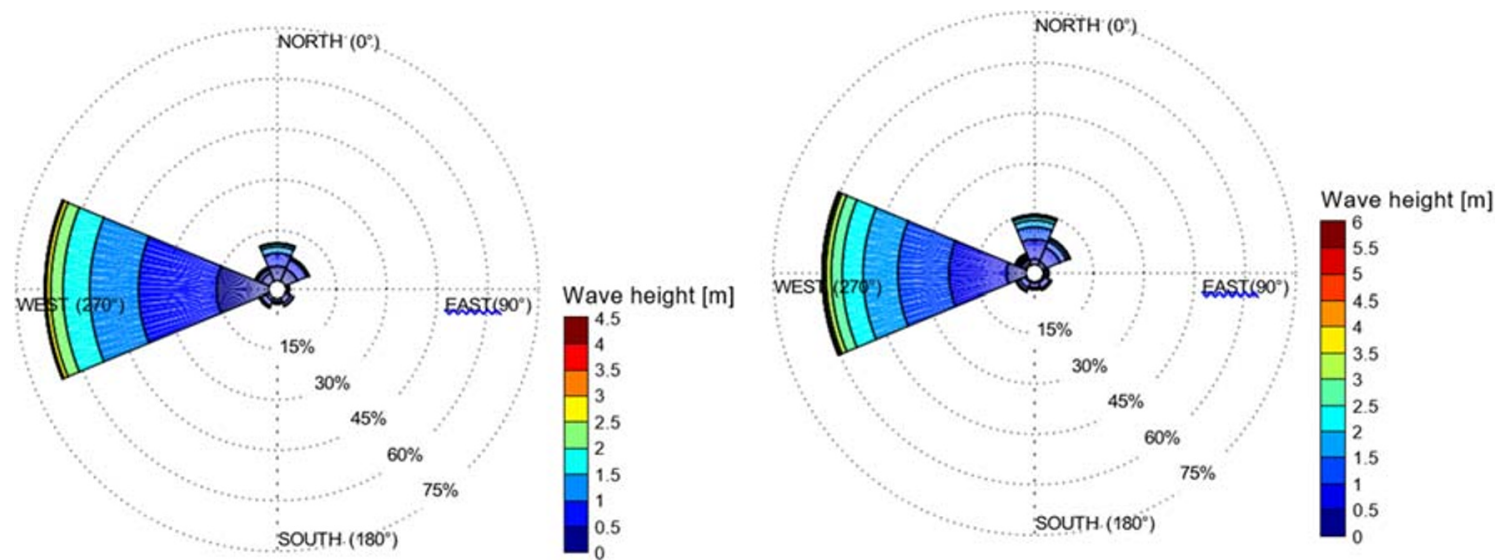

Fig. 5 Wave roses from the buoy 10,411 located in Hirtshals area. The wave roses contain data for the period August 1999 to August 2012. Left: Hm0 summer. Right: Hm0 winter 
north from Nørlev Strand. About a $26 \%$ of the data is missing from buoy 1041. Data from buoy 1012 is used to complete data gaps in wave heights and to obtain a series from January 1999 to December 2012. $H_{m 0}$ is well correlated, $T_{p}$ is poorly correlated due to a failure in buoy 1041 and $\theta_{m}$ cannot be compared since 1012 contains non-directional data. The linear correlation factor for $\mathrm{H}_{\mathrm{m} 0}$ between both buoys is 0.94 , and there is a proportionality factor of 0.79 , which is used in the completion of data. After data completion, the missing data of $\mathrm{H}_{\mathrm{m} 0}$ is reduced to $3 \%$ of the total data.

The most uncut parameters are $H_{\max }, T_{p}$ and $T_{z}$. To derive $H_{m 0}$ from $H_{M A X}$ it is used the derived expression (Liu and Frigaard 1999):

$$
H_{m 0}=1.07 \cdot 1.94 H_{M A X}
$$

In the same line, according to Badulin 2014, $T_{a}$, the mean over spectrum period defined by Hwang et al. 1998 is equivalent to the $T_{z}$. Moreover, Badulin 2014 states that all periods are related by a certain coefficient. In the case of $T_{P}$ and $T_{z}$, the relation according to Hwang et al. $1998^{7}$ is

$$
\frac{T_{P}}{T_{Z}}=1.29 \pm 0.14
$$

The following filters are applied to the data:

- The data is first checked for negative wave height and period values, and for too high or too small period values. Wind generated waves, as these, have wave periods in between $1 \mathrm{~s}$ and $30 \mathrm{~s}$, Andersen 2016.

- Where possible, wave height and wave period relations are used to check the existence of outliers.

- Measured waves are stable; in other words, they are not breaking either by depth, neither by steepness. Under storm, waves with steepness, $H / L$, larger than $1 / 10$ are hardly ever found. Waves also become unstable when the relation $H_{S} / h \leq 1 / 10$ is met, Andersen et al. 2014

No continuous water level measurements of the necessary resolution are available around Nørlev Strand; therefore, the water level will not be analysed thoroughly during the study period. Tide data, instead, is obtained from the Danish Meteorological Institute (DMI). The data is recorded at Hirtshals port. According to the 2017 tide tables from the DMI, the maximum spring tide has a magnitude of $0.4 \mathrm{~m}$ while the minimum spring tide has a magnitude of $-0.4 \mathrm{~m}$. Regarding current data, there has not been any measurements in the area for more than 20 years. Thus, it is not considered in this study. Wind speed and direction are measured at Hirtshals port, with UTM coordinates $[557,550,6,383,950]$, from February 1996 until December 2017. Wind data is used to understand climate variability in the area. Finally, profile measurements are collected every two to 4 years using total station, GPS and echo sound technology. Data under water is taken approximately every $2 \mathrm{~m}$, while data measured over water is taken according to the morphology. The transect data is interpolated using a linear function to obtain equally spaced data points.

\section{Evaluation of the average wave climate}

The different wave parameters change both temporally and spatially, i.e. in the different seasons and depending on the geography. With the purpose of dealing with homogeneous events in the description of the average climate, wave records are first divided into eight groups based on their direction, to account for the geographic variability, and subsequently divided in winter and summer events. Based on the oceanographic definition of winter and summer, winter ranges from October to March, while summer ranges from April to September. This division was also done by Li et al. 2014 . This division is made for wave height, wave period and, subsequently, wave direction.

The average value of wave height and period is calculated for each direction and for winter and summer. Since waves coming from the north and the west account for $75 \%$ of the incoming waves, the average wave climate depiction is based mostly on these two groups of data. In the case of the direction, the mean value is not calculated, but the mode. Variations of the mode of every direction sector are analysed.

\section{Incident wave height - Significant events}

Climate change may be responsible for increase in numbers and intensity of storm events as discussed in Graeme 2011 and as warned by the Intergovernmental Panel on Climate Change (IPCC). The incidence of medium to large wave height and wind events is analysed. These events, from now on referred to as significant events, are defined as those independent events that exceed a certain threshold, and they are obtained by using the principles of extreme value analysis (Morton and Bowers 1996).

In the case of wave heights, the threshold is established as the $125 \%$ of the average significant wave height calculated from the wave time-series. This value is $1.43 \mathrm{~m}$. Regarding the independence criterion, two events are independent if there are at least $24 \mathrm{~h}$ between them. If there are less than $24 \mathrm{~h}$ between two wave heights that surpass the threshold, they belong to the same cluster of data (pp. 42-43, Liu and Frigaard 1999). A similar criterion is applied to wind; however, the threshold is selected as the $155 \%$ of the average wind speed calculated from the wave time-series. This is done to obtain several events of the same order as the number of wave events. The threshold value is $11.4 \mathrm{~m} / \mathrm{s}$. 


\section{Numerical simulations}

To assess the effects of the above-mentioned parameters on the erosion, a numerical model is used. By running the model, it is possible to determine which parameter has larger influence on the alongshore sediment transport of Nørlev Strand. A value of reference is taken for each parameter, and the model is run with it. This value of reference is, in principle, the actual quantity which can be found at Nørlev Strand. From this simulation, a reference net sediment transport for that parameter is obtained. Consecutively, the model is run again with the reference value varied in a fix magnitude, and a new figure of the sediment transport is obtained. The used increments are $\pm 10 \%, \pm 25 \%, \pm 50 \%, \pm 75 \%$ and $+100 \%$. $-100 \%$ is not considered, as it implies the input parameters is 0 which in most cases makes no physical sense or creates model instabilities. In the case where wave direction is tested, making percentage increments does not suit the study; thus, the model is run for directions every $15^{\circ}$. It is important to note that only the parameter under analysis varies, while the rest remain constant.

Numerical modelling is used to analyse how the variation of simple hydrodynamic and morphological parameters affects alongshore transport at Nørlev Strand. Changes in flux patterns can be linked to changes in the erosive or sedimentary potential in the coast (Silva et al. 2016) (Davidson-Arnott and Pollard 1980). The technical information about the numerical model used in this section is based on the user manual of Littoral Processes FM, from the Danish Hydraulic Institute, DHI 2016. The parameters investigated have mean grain size, water level, wave height, wave period, duration of the wave event, bed roughness and wave direction. According to the recommendations of the user manual, the latter parameter is tested in the model by keeping a constant wave direction input and varying the coastline alignment.

Littoral Processes FM is a 1D model that simulates alongshore transport. The tool agglutinates four different numerical models: transport in a point, littoral drift, table generation and coastal evolution. For this study will only use littoral drift. It consists of two main operations. First, it solves the hydrodynamic equations, including wave propagation towards the coast, shoaling and breaking and calculation of driven forces. These forces come from the radiation stress gradient and the momentum balance equation in the cross- and longshore direction. Second, it calculates the sediment transport from the generated hydrodynamic conditions and the sediment characteristics. The following assumptions are made:

- Sediments are purely granular and non-cohesive.

- Morphological changes in the cross-shore directions are negligible.

- Bathymetry contours are quasi-parallel to the coastline and the profiles are perpendicular to them.

- The predominant current direction is longshore.

\section{Hydrodynamic inputs}

The inputs are root mean square wave height, $H_{r m s}$, zero upcrossing wave period, $T_{z}$, mean wave direction, $\theta_{m}$, spreading factor, wave duration in percentage of the year, water level and currents. The spreading factor is set as the default value, 0.5. $H_{r m s}$, and $T_{z}$ are calculated from $H_{m 0}$ and $T_{p}$ respectively. The relation between $T_{p}$ and $T_{z}$ was enunciated in Eq. (3.2). $H_{r m s}$ is obtained from $H_{m 0}$ using (Liu and Frigaard 1999):

$$
\begin{aligned}
& H_{r m s}=1.13 \bar{H} \\
& H_{S}=1.6 \bar{H} \\
& H_{m 0}=1.07 \cdot H_{S}
\end{aligned}
$$

These variables can be set as constants during the simulation or as variables. In this study, the variables are set as constant, using bulk statistics calculated in the wave climate analysis. Since there is neither water level nor current data, in the case of the water level it is only the tidal variation that is considered as model input; as for the currents, the model calculates wave generated currents. The model uses the Rayleigh spectral description for individual wave heights (user decision). Rayleigh is a conservative formulation since it does not take into consideration wave breaking due to limited water depth (Liu and Frigaard 1999). Therefore, the waves that propagate towards the coast are larger.

\section{Morphological input}

The bathymetry of the coastal stretch is described in the model by using only cross-shore profile data. Since the model does not consider morphological changes when calculating sediment transport, the input is simplified to only one cross-shore profile. The actual sediment transport at Nørlev Strand is not sought for, and by having a uniform description of the coastal stretch, computational time is reduced, and the focus of the investigation remains on the variation of the aforementioned parameters. Other morphological inputs include critical Shield's parameter, Nikuradse bed roughness and fall velocity.

The critical Shields parameter $\theta_{c}$ depends on the sediment fluid parameter:

$S_{w}=\frac{D_{50} \sqrt{(s-1) \cdot g \cdot D_{50}}}{4 \nu}$

Having determined a value of the sediment fluid parameter, $\theta_{c}$ can be read from the Shields diagram. The value obtained of the critical Shields parameter is very close to the default value (0.0045), which the user manual recommends using.

The formulation used to calculate the Nikuradse bed roughness is based on Liu 1999. Bed roughness is defined as the interval: 
$H_{r} \leq \kappa \leq 4 \cdot H_{r}$

which depends on the ripple steepness $H_{r}$ :

$\frac{H_{r}}{L_{r}}=0.182-0.24 \cdot\left(\theta^{\prime}\right)^{3 / 2}$

where $\theta^{\prime}$ is the effective Shields parameter calculated in Eq. (A.1), and $L_{r}$ is the ripple length.

$L_{r}=2 \cdot A$

Due to lack of data to define the grading coefficient according to the specifications of the software, the sand is assumed uniform. For uniform sand it is required to input fall velocity. According to Ahrens 2000, the following formulations lead us to a determination of the fall velocity with a small error. First, the fall velocity is defined as:

$\omega=\frac{C_{1} \cdot \Delta \cdot g \cdot d^{2}}{\nu}+C_{t} \sqrt{\Delta \cdot g \cdot d}$

where $\mathrm{A}$ is the Archimedes buoyancy index, and $d$ is the characteristic diameter, in this case taken as $D_{50}$. The Archimedes buoyancy is defined as:

$A=\frac{\Delta \cdot g \cdot d^{3}}{\nu^{2}}$

Finally, the coefficients $C_{1}$ and $C_{t}$ are:

$$
\begin{aligned}
& C_{1}=0.055 \tanh \left(12 A^{-0.59} \cdot e^{-0.0004 \cdot A}\right) \\
& C_{t}=1.06 \tanh \left(0.016 \cdot A^{0.5}\right)
\end{aligned}
$$

Appendix A.1 contains the equations used to obtain the effective Shield's parameter, which is used to calculate the Nikuradse rough parameter.

\section{Analysis}

This session presents the results of the analysis of the historical wind and wave data. Besides the study of wave heights, periods and directionality, we include considerations of climate change, particularly discussing the increase in the number of significant wave events from 1999 to 2011, but also by looking at national storm records from 1981 to 2011.

\section{Wave height}

The first characteristic analysed is the evolution of the annual average significant wave height, $H_{m 0}$. Figure 6 is divided in two plots. The top plot contains the evolution in time of $H_{m 0}$ for waves coming from directions $250^{\circ}$ to $295^{\circ}$, while the bottom plot contains waves coming from directions $340^{\circ}$ to $25^{\circ}$. There is a relatively constant trend for the wave heights in both plots. Westerly waves vary around $1.3 \mathrm{~m}$, while northerly waves vary around $1.1 \mathrm{~m}$. For westerly waves, the dispersion is also smaller than for northerly waves. The largest waves come generally from the west, with some exceptions, like the winters 2005 and 2010, and the summers 1999, 2001, 2008 and 2010. These larger events linked to a direction, other than the principal one, could be related to erosive processes. Since the coastline form is adapted to the principal direction, waves with a different angle of incidence arrive with a more
Fig. 6 Annual values of mean $\mathrm{Hm} 0$ divided into winter (blue cross), summer (yellow triangle) and all data events (red circle). Top: sector $\left[250^{\circ}-295^{\circ}\right]$. Bottom: sector $\left[340^{\circ}-25^{\circ}\right]$
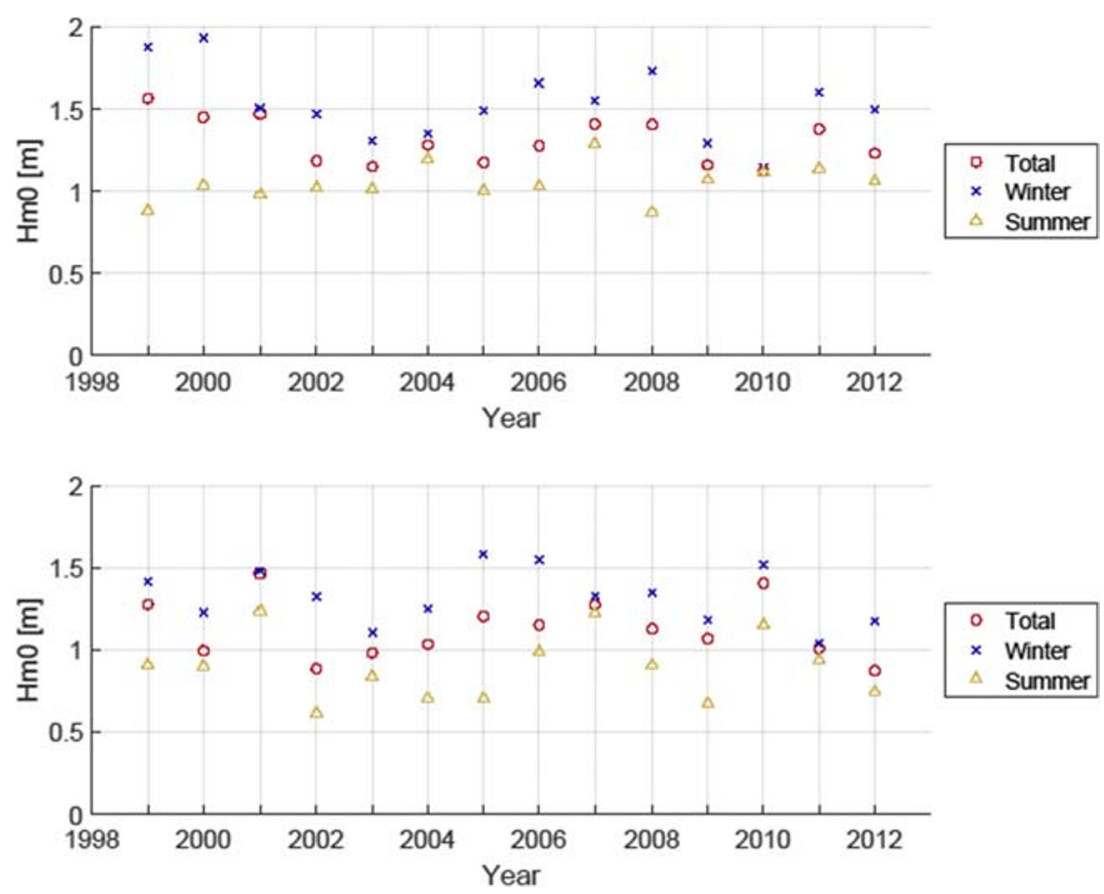
oblique angle which induces longshore transport. Finally, the largest average winter and summer $H_{m 0}$ are registered from 1999 to 2001, while the milder years are 2002 and 2012.

\section{Wave period}

Waves coming from the west have larger periods than waves coming from the north, see Fig. 7. This is in line with the fact that the largest fetches are found in the sector $\left[250^{\circ}-295^{\circ}\right]$. Larger fetch leads to loss of energy and elongation of the wave period. Waves coming from the north are more locally generated, and their periods are generally shorter. In the relation winter-summer, winter waves present larger periods than summer waves. In 2010 , the largest average period from northerly waves was measured, while in 1999 the largest one for westerly waves was measured. The shortest average period was registered in 2002 for northerly waves, and in 2012 for westerly waves.

\section{Wave direction}

To characterize wave directions, mode per sector is used instead of the average, see Fig. 8 . The mode in the sector $\left[250^{\circ}\right.$ $295^{\circ}$ ] is very stable around $270^{\circ}$. However, there is a shift in the mode of winter waves from 1999 to 2001. Regarding sector $\left[340^{\circ}-25^{\circ}\right]$, most of the waves concentrate in between $0^{\circ}$ and $25^{\circ}$, with a large dispersion within. It seems that both summer and winter modes tend to shift from $20^{\circ}$ to $5^{\circ}$ during the study period. In 2001 in both sectors, there is a large shift in the mode of the wave direction from summer to winter. This shift is of about $25^{\circ}$ in the west sector and $15^{\circ}$ in the north sector.

\section{Frequency of significant events}

The number of significant wave height events (as defined in "Methodology" section) seems to increase continually from 1999 to 2012 in Hirtshals, while the significant wind events decrease. As there is a very strong correlation between wind and waves, the difference between the two trends can only be explained (minus errors) by the directionality. While the number of significant events for wind speeds did not increase when looking at all wind directions, the number of significant events with wind directions affecting the formation of the waves reaching the coast has increased, generating a rise in significant wave events shown in Fig. 9.

It is not in the scope of this paper to find the increase in the number of significant events, but to find out whether there is a tendency which could explain the increasing erosion experienced at Nørlev Strand.

\section{Climate change}

The Danish Meteorological Institute, DMI, released a report in 2012 that included a list of storm events in Denmark since 1891. Here, storm events are classified in four classes based on wind speeds (class I: 17$21 \mathrm{~m} / \mathrm{s}$, class II: $21-24.5 \mathrm{~m} / \mathrm{s}$, class III: $24.5-26.5 \mathrm{~m} / \mathrm{s}$ and class IV: above $26.5 \mathrm{~m} / \mathrm{s}$ ). We have here transposed the storm data into a diagram in order to give an overview on the historical situation in Denmark. An average over the storm classes for each year is made and the duration reflects only the number of days reported for the same storm condition (low accuracy in terms of hours of
Fig. 7 Annual values of mean $\mathrm{Tp}$ divided into winter, summer and all data events. Top: sector $\left[250^{\circ}\right.$ $295^{\circ}$. Bottom: sector $\left[340^{\circ}-25^{\circ}\right]$
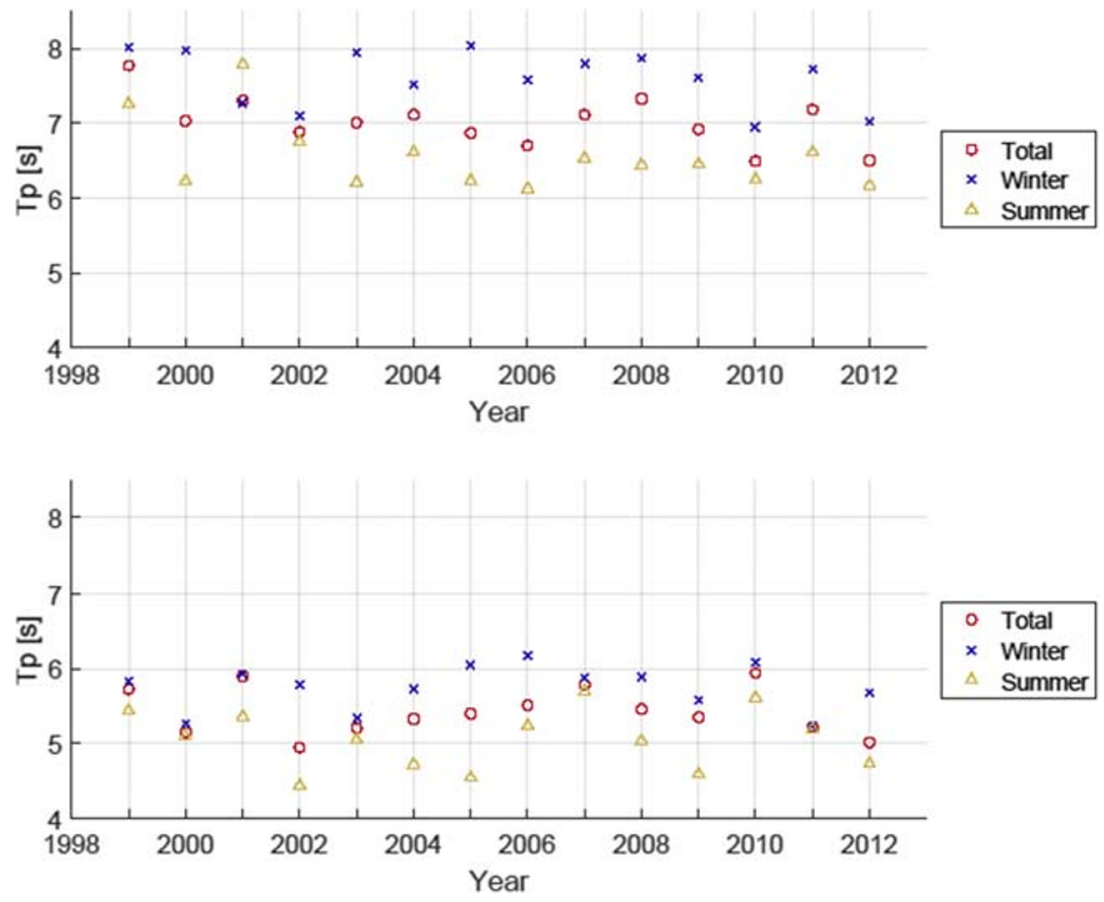
Fig. 8 Annual mode of mean wave direction separated in winter and summer event. Top: sector $\left[250^{\circ}-295^{\circ}\right]$. Bottom: sector $\left[340^{\circ}-25^{\circ}\right]$
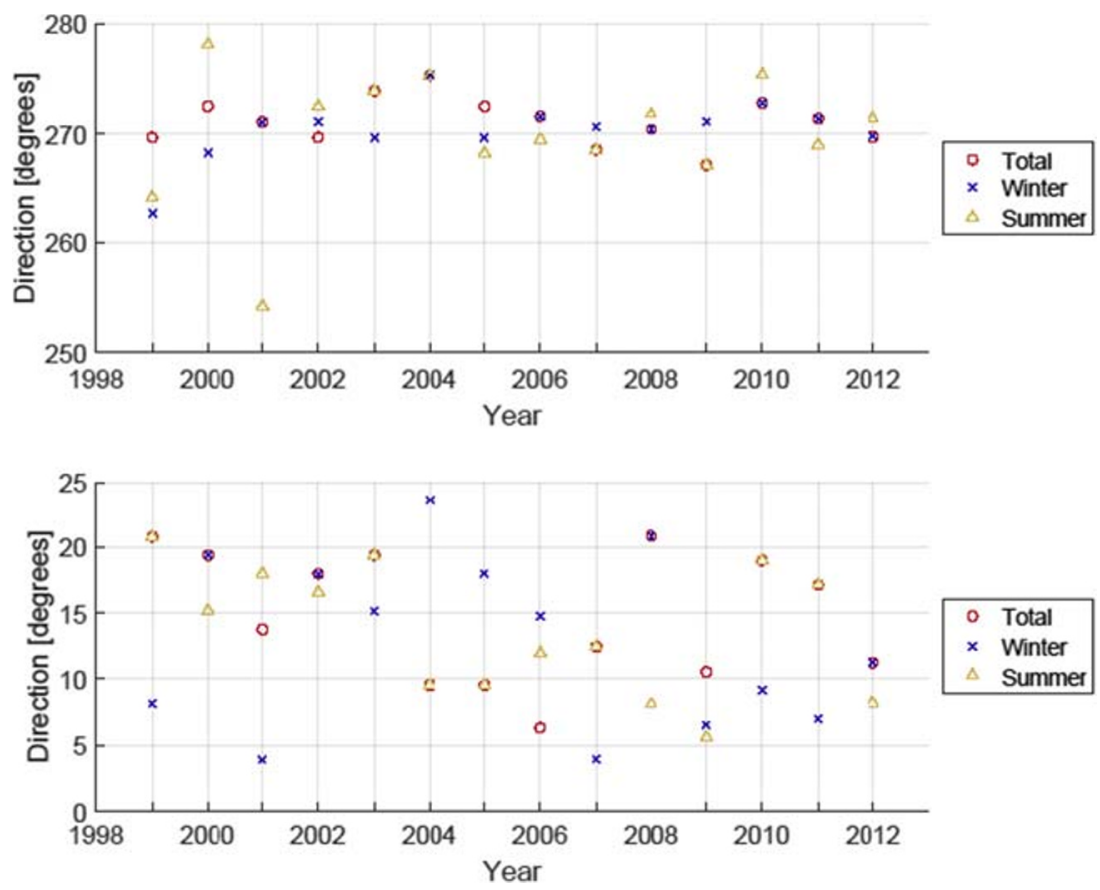

duration). We have then added the average coastal retreat obtained as an average of the three values at three heights: $0 \mathrm{~m}$ height (coastline), $1 \mathrm{~m}$ height and $4 \mathrm{~m}$ height as presented in "Area of study" section (Fig. 10).

We can see a good correlation between storm events and coastal retreat, with no erosion present between 1995 and 1999 as consequence of a lack of storm events.

In the same report, climate variations are reported in terms of temperature, accumulated precipitation and cloud cover. While it seems that climate change has not significantly affected the number of storm events or their intensity over the past 120 years, if we consider that our data at location runs from the early 1970 s to the present, we may see an increase in duration and number of events today compared to the early records at Nørlev Strand. We do not here consider increase in duration and number of events as effect of climate change; however, the accumulated precipitation does seem to be increasing instead (Fig. 11). Given the geological and morphological characteristics of the coast, heavier rain fall may increase water table elevation at the foreshore and decrease the cohesion of the sand in cliff and facilitate landslides and erosion. This possibility was first investigated by Bryant 1985 and backed up more recently in Jenkins et al. 2008. Because of the geology of the Danish west coast - dominated by different types of sands - this hypothesis may play an important role, and there should be consideration on implementations into prediction models that take precipitation into account in the erosion evolution.
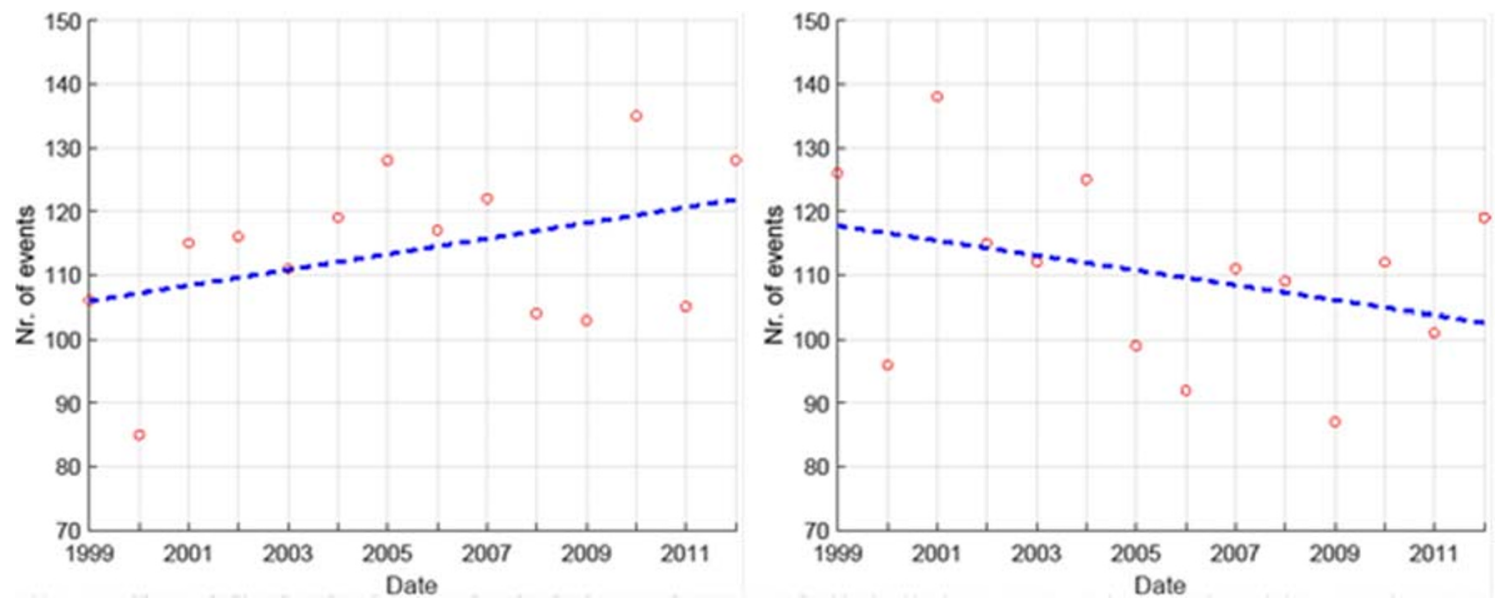

Fig. 9 Left: frequency of wave height exceedance in Hirtshals. Right: frequency of wind speed exceedance in Hirtshals 


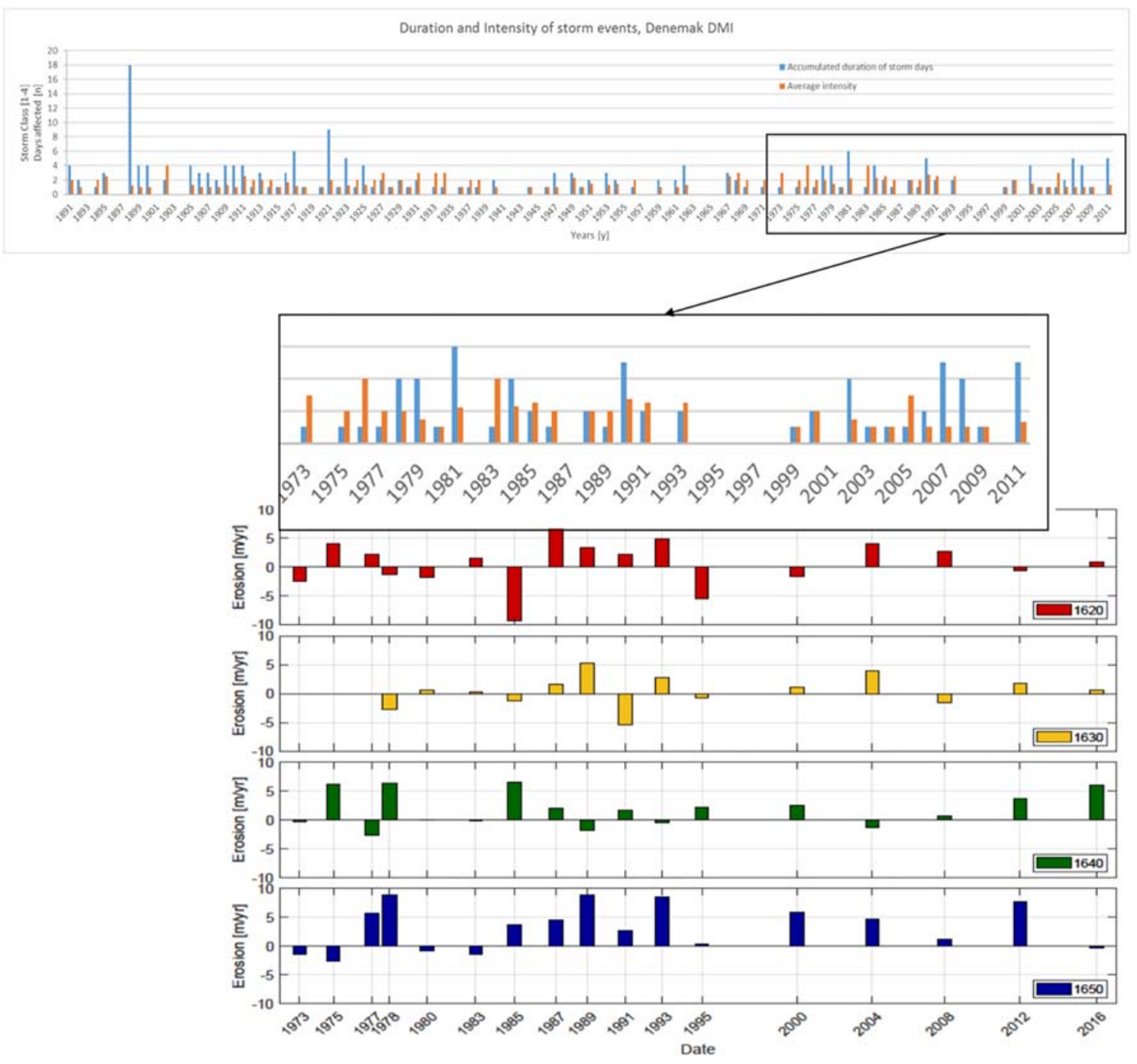

Fig. 10 Average over storm classes for each year. The duration (top, in blue) reflects only the number of days reported for the same storm condition. (top, orange: intensity). For the early 1970s, we present the evolution of the average annual erosion for the four profiles considered in "Area of study" section

\section{Results}

Based on the described methodology, the results from the numerical model for a specific parameter are presented as the curve of the variation of sediment transport with the specific parameter. A zero in the curve indicates no variation with respect to the reference value. If the net sediment transport becomes $-100 \%$, this should be understood as no net sediment transport being generated. A negative increment below $-100 \%$ represents sediment transport in the opposite direction.

\section{Mean grain size and fall velocity}

The reference mean grain size, $D_{50}$, is $0.233 \mathrm{~mm}$, which is that of Nørlev Strand. Since the fall velocity is dependent on the mean grain size, they are considered together (Eq. 3.8)
(Fig. 12). With very small grain sizes, the waves wash away all sediments. This can be seen in the left part of the plot where the curve tends to infinity. Continuing the curve development, there is a critical part in which, with increasing grain size, the sediment transport decreases until a minimum. This minimum corresponds to $25 \%$ larger than the reference $D_{50}$. After this point, it increases again and becomes quite stable, showing minimal growth rate. This could be caused by the increment in bed friction due to a larger grain size, which leads to more wave breaking. $D_{50}$ has a major influence in the configuration of the beach that cannot be estimated with these numerical simulations. First, the beach profile shape is very sensitive to $D_{50}$; a larger sediment grain size results in a steeper profile (see Eq. 4.1, Dean 2003). This is well-known in beach nourishment practice, where it is common to use a slightly larger mean grain size to achieve smaller refill volumes. 
Annual Accumulated Precipitation, Denmark 1874-2011

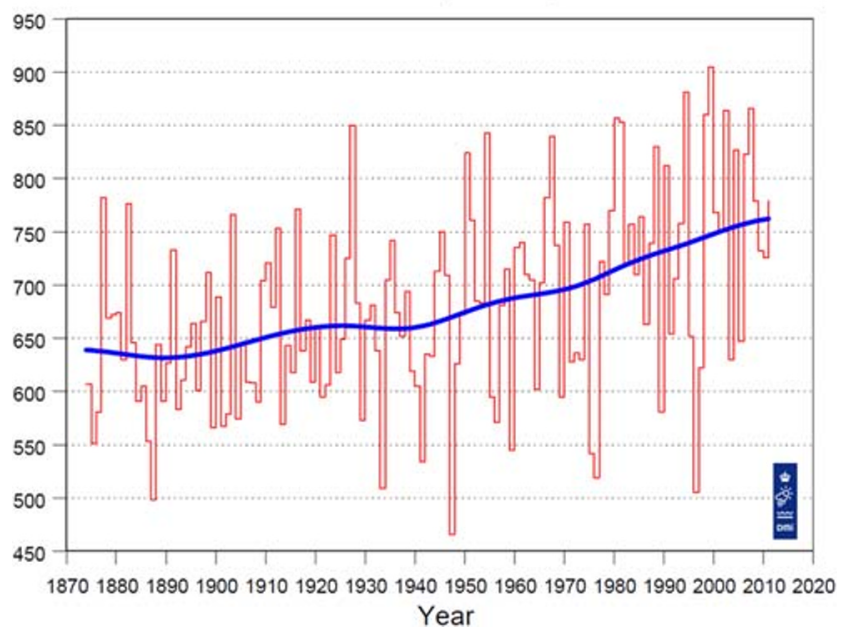

Fig. 11 Annual accumulated precipitation in Denmark from 1874 to 2011. Source: DMI

$h(y)=A \cdot y^{2} / 3$

$A=0.067 \cdot \omega^{0.44}$

where $h$ is the water depth at a distance $y$ from the shoreline, both in in $m ; A$ is the profile scale parameter in $\mathrm{m}^{1 / 3}$, and $\omega$ is the fall velocity in $\mathrm{cm} / \mathrm{s}$. Equation 4.1 is the beach equilibrium profile, which depends on the mean grain size through the fall velocity. According to this equation, the larger the mean grain size, the larger the water depth in the profile equilibrium. Subsequently, the effect of water depth change must be added to the effect of the grain size variation.

Second, the type of wave breaking depends on the beach slope (see Eq. 4.2, USACE 2002), which becomes steeper with larger mean grain size and milder with smaller grain mean size.

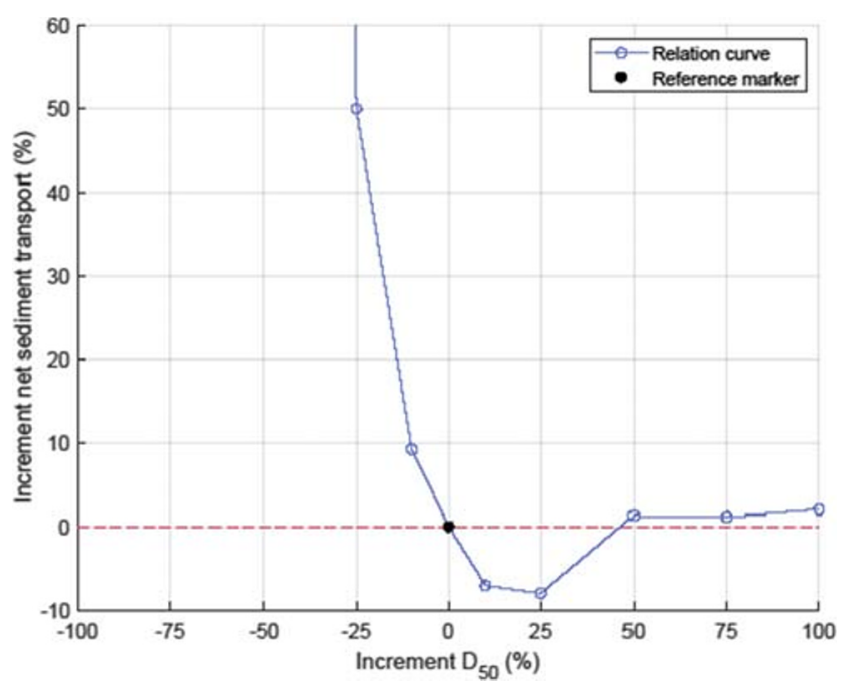

Fig. 12 Increment of net sediment transport in relation to mean grain size $\xi_{0}=\tan \beta\left(\frac{H_{0}}{L_{0}}\right)^{-\frac{1}{2}}$

where $\beta$ is beach slope, $\mathrm{H}_{0}$ and $\mathrm{L}_{0}$ are wave height and wave length in deep water, and $\xi_{0}$ is known as the Iribarren number, or surf similarity parameter. It predicts the way that waves break. The steeper the beach, the larger $\xi_{0}$, and the more turbulent the breaking becomes (USACE 2002). Turbulent breaking implies more stirring, and more sediment in suspension, which increases potential transport, see Fig. 13.

For the sake of simplicity, it is assumed that the distribution of the particle is uniform in the cross-shore profile. This is not necessarily true. In fact, there is a tendency for the particles to be sorted by size across the profile, both spatially and temporarily (Medina et al. 1994). Typically, the coarser grain particles are located in the breaker zone, while the finest particles can be found towards both offshore and onshore, depending on the energy dissipated (Wang et al. 1998). As there is no available data to characterize sorting, the mean grain size distribution at Nørlev Strand is assumed uniform.

The effects of the main grain size variation on the sediment transport cannot be properly quantified, but Fig. 13 gives an idea of what to expect if nourishment projects are carried out in the area.

\section{Water level variation}

The relation between the water level variation and the net sediment transport is not linear, but they are proportional (Fig. 14). The smaller the water level variation considered, the smaller the sediment transport obtained. The reference value is taken as the spring tide $0.40 \mathrm{~m}$.

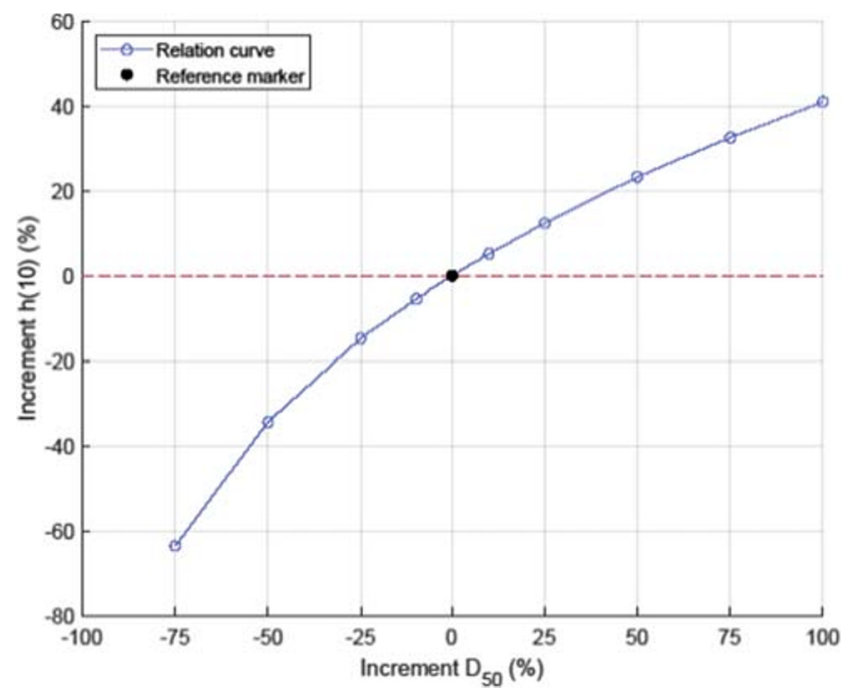

Fig. 13 Relation between water depth at $10 \mathrm{~m}$ distance from the shoreline and grain sediment size 


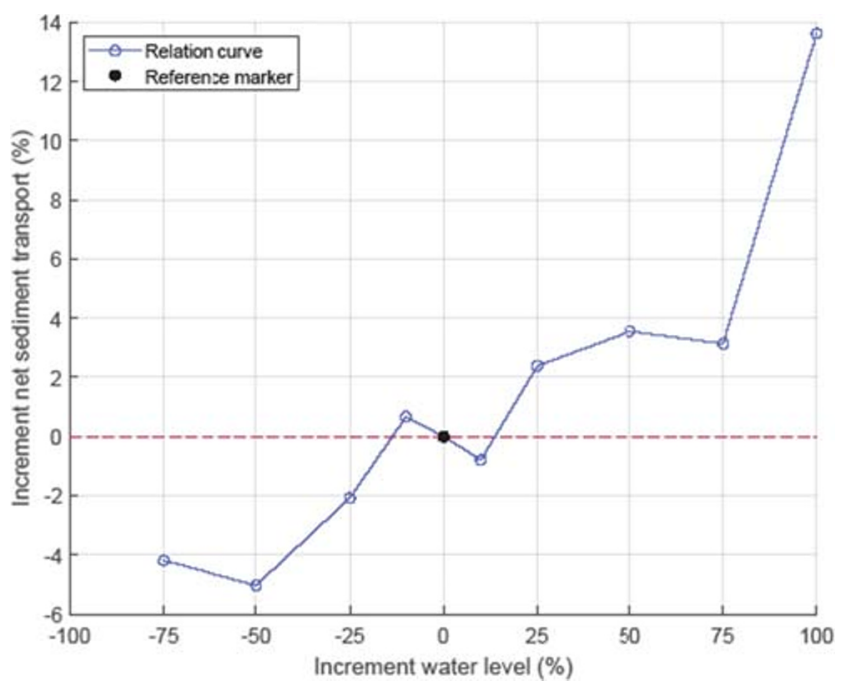

Fig. 14 Increment net sediment transport with respect to water level

The curve displayed in Fig. 14 is, unfortunately, showing odd results, which can be due to set up errors. It is expected that larger water levels lead to larger sediment transport without the presence of breaks in the curve. The plot is expected to have a parabolic shape, with the same gradient it shows currently.

A higher water level allows for larger wave heights to approach the coast. The water depth increases, and waves that would usually break offshore will move forward onshore. The waterline reaches a higher point, potentially generating erosion at the dune foot.

\section{Wave height}

The net sediment transport is very sensitive to the wave height, see Fig. 15. As seen from the CERC formula (Eq. 4.3), the term

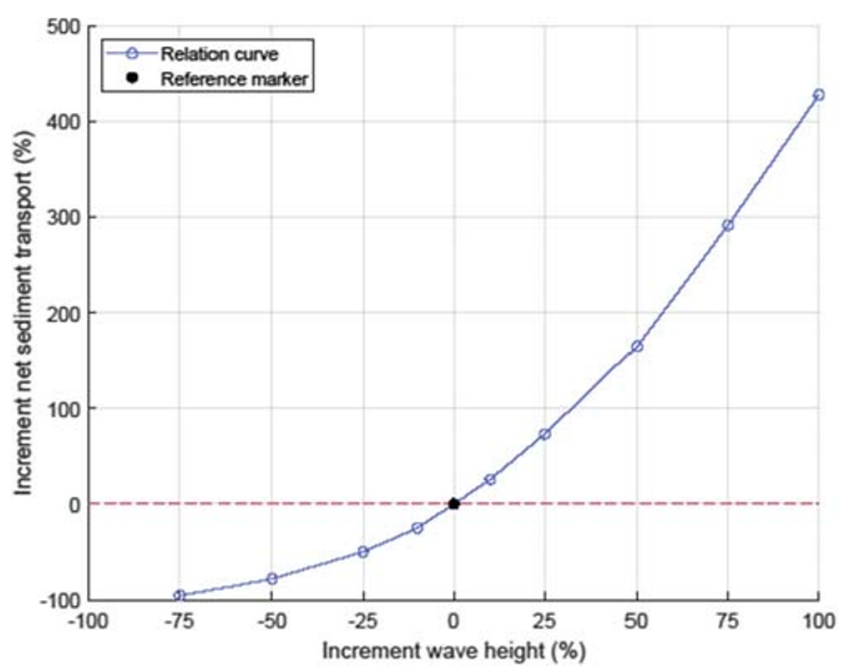

Fig. 15 Increment of net sediment transport with respect to the significant wave height correspondent to the breaking wave height is to the power of 2.5

$Q=\frac{5}{8} \frac{H_{b}^{3 / 2} \sqrt{\frac{g}{k}}}{(1-p) \cdot(s-1)} \cdot \frac{\sin \left(2 \cdot\left(\beta-\alpha_{b}\right)\right)}{2}$

In Fig. 10, the relation in between $H$ and the net sediment transport has an exponential tendency. The reference wave height is $1.4 \mathrm{~m}$. The highest transport is obtained by doubling the wave height. Doubling the wave height has implied quadruplicating the net sediment transport.

The wave height is the main variable when referring to the energy content of the waves, and at the same time, in the simulations the main input source are the waves. The total energy density per unit area of the water waves is defined as (Andersen et al. 2014):

$E=\frac{1}{8} \cdot \rho \cdot g \cdot H^{2}$

where, again, the wave height term appears to the power of 2 .

\section{Wave period}

According to the results of the sensitivity analysis (Fig. 16), in principle the net sediment transport increases with increasing wave period. Van Gent et al. 2008 have also shown this effect. The reference peak period is $4.7 \mathrm{~s}$. This relation is not completely clear, and Fig. 16 shows some odd behaviour for small periods. With substantial periods, the waves will become more stable and their Iribarren number will also decrease. Consequently, breaking is less turbulent, reducing the erosive tendency.

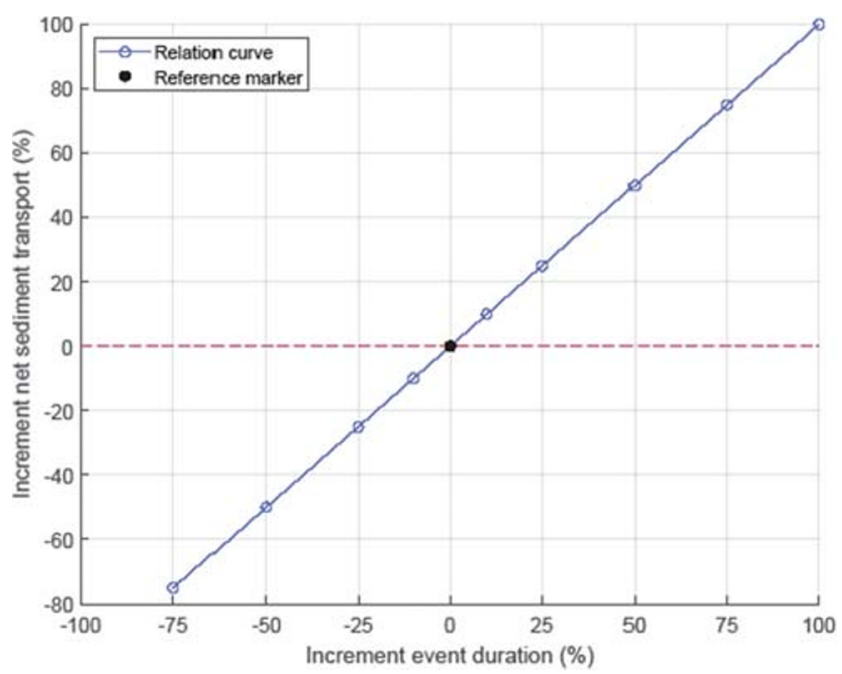

Fig. 17 Increment of net sediment transport with respect to the event duration 


\section{Event duration}

The event duration is linearly proportional with the net sediment transport. The larger the event, the larger the energy associated to it, and therefore the transport, see Fig. 17.

\section{Bed roughness}

The values of the bed roughness are previously calculated using theoretical formulations. From this calculation, a range of possible values are obtained, going from 0.0087 until 0.0869 . These are obtained by using wave heights of the average wave climate. As seen in Fig. 18, bed roughness and sediment transport are inversely proportional. The larger the bed roughness, the larger the friction with the bottom and the more wave energy is dissipated.

\section{Coastline alignment}

In this simulation, the waves always come from a constant direction, and it is the coastline that changes its angle. Testing coastline alignment variation is, in turn, the way of testing the impact of wave direction in the sediment transport in this numerical model. Directions are tested every $15^{\circ}$, including $310^{\circ}$, which is the reference value. The reference wave forms an angle of $275^{\circ}$ with respect to the true north. This means that the angle of incidence of an average wave is $35^{\circ}$.

A net sediment transport of $-200 \%$ means that a certain coastline alignment has led to a value of net sediment transport of equal magnitude as the original, but with an opposite direction. This is the only case where this behaviour is displayed, see Fig. 19. The maximum of the net transport is found when the normal vector to the coastline forms an angle of $235^{\circ}$ with true north, and it is a southern directed transport. This is opposite to the predominant transport direction. In that case, the coastline alignment forms approximately $40^{\circ}$ with the reference wave direction.

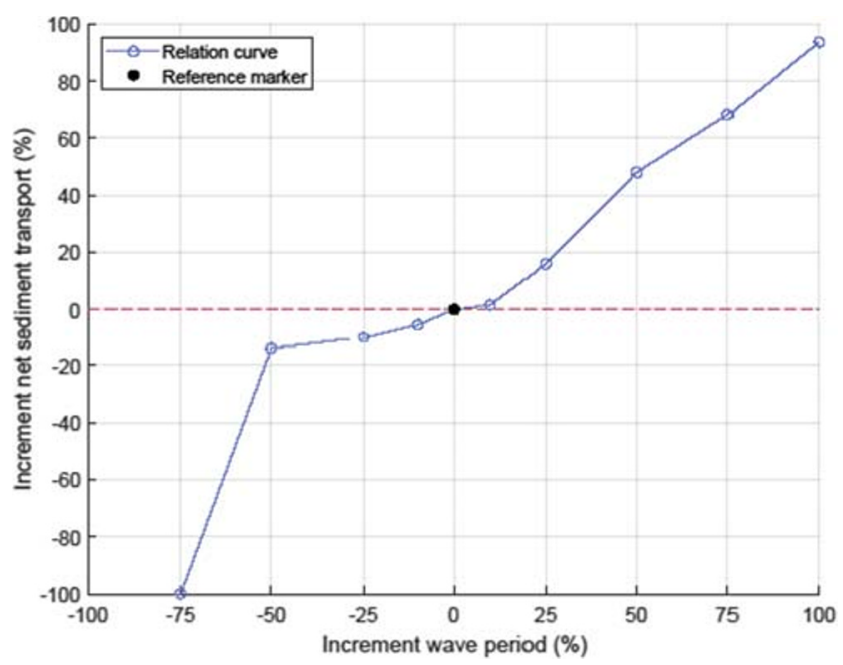

Fig. 16 Increment of net sediment transport vs the wave peak period

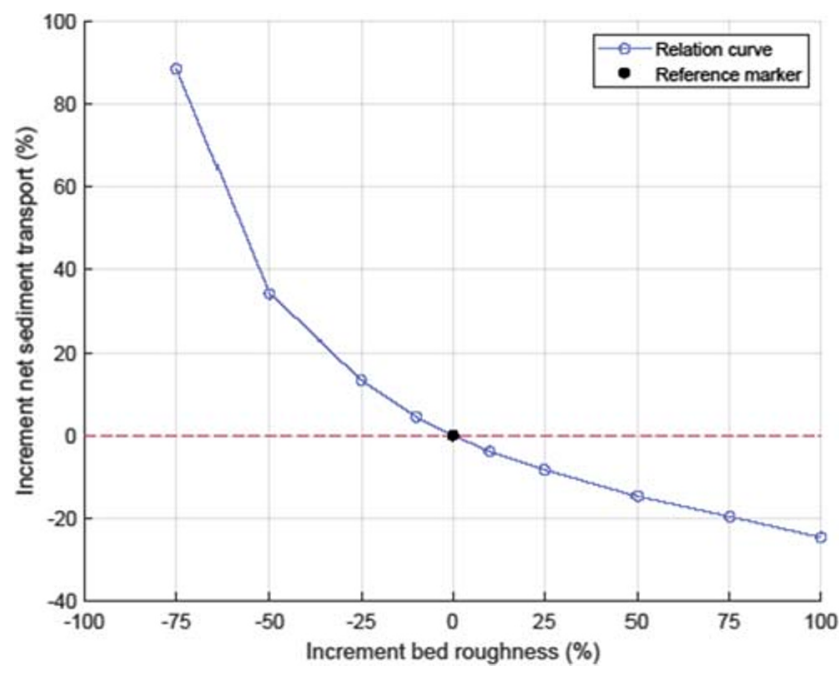

Fig. 18 Increment of net sediment transport with respect to bed roughness

When the waves from both north and west affect the coast during the same period, there is gross transport flowing both towards the north and the south. Consequently, the net sediment transport is reduced during those periods. This could be the case in years when the average wave height from northerly waves increased.

When the normal to the coastline alignment forms in between $190^{\circ}$ and $85^{\circ}$, the wave input in the model comes "from land". Therefore, the sediment transport is zero. When the angle is smaller than $85^{\circ}$, and until it reaches $0^{\circ}$, only fractions of the waves coming from the north have an effect on the coast, and therefore, there is small transport. This transport tends to be zero when the coastline becomes perpendicular to northerly waves.

The maxima for northerly directed transport is achieved with a coastline alignment of $325^{\circ}$, which means that the angle of incidence of the test wave is $55^{\circ}$. It is expected that a larger

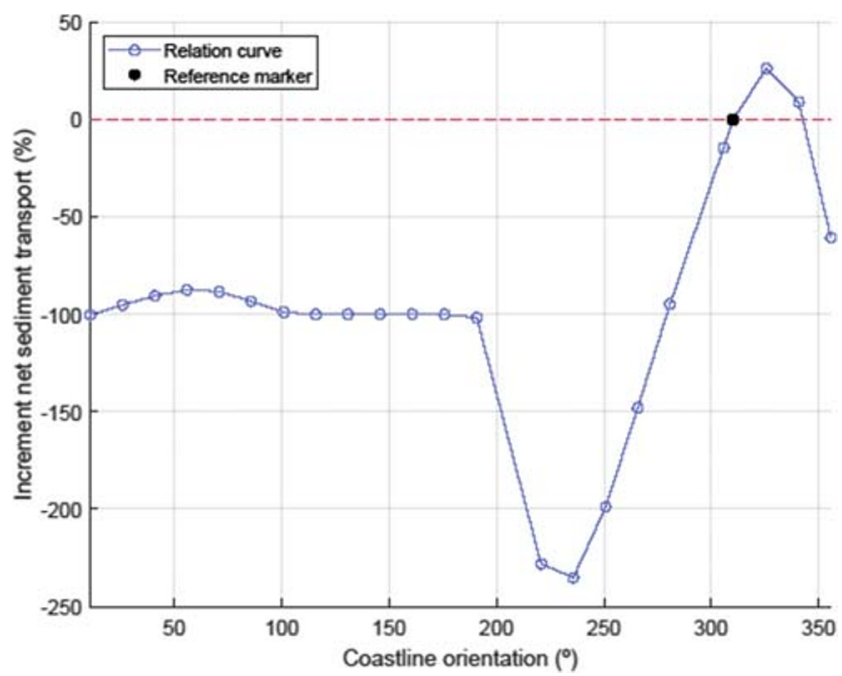

Fig. 19 Variation of the sediment transport in relation to the coastline alignment 
transport would have been achieved by testing a coastline alignment of $320^{\circ}$.

To conclude, it can be expected that shifts in the mean wave direction, particularly towards south, enhance the magnitude of the net sediment transport and the erosive potential.

\section{Conclusions}

At Nørlev Strand, as the morphology of the coast is experiencing irreversible changes, intensification of climatic events is translated into greater risk of damage of the properties in the coast. In terms of engineering protection works, the construction of revetments, for example, can protect the houses from the effects of the storms, but it does not prevent the relapse of the coastline, which means that without a constant campaign of beach nourishments, the revetment toe will eventually erode and fail.

This study has looked into the influence of different parameters on the costal erosion in Nørlev Strand.

We conclude that some parameters are, at present, contributing to the erosion; others have a potential influence, no influence or unknown influence. As the erosion in Nørlev is a superimposition of different factors, we tried to quantify the influence of each one of them with numerical simulations.

- The first most important parameter influencing erosion is, not surprisingly, the wave height.

The data analysis at the location for the past 70 years did not reveal an overall increase in wave heights, but there was a constant increase in frequency of significant events recorded. Winter events are $1 \mathrm{~m}$ to $1.5 \mathrm{~m}$ larger than summer events, and therefore winter events are more relevant in the quantification of sediment transport. Therefore, this parameter is currently increasing erosion at the location. Additionally, the numerical analysis showed that an increase in wave height of $25 \%$ would increase the sediment transport of $80 \%$ approximately, following an exponential trend. This implies that if wave heights increase (increased storminess events combined with higher water levels), the significant wave height will increase at location in the next years, and so will the erosion induced by wave height with the trend showed in this study.

- The second most important parameter affecting the costal erosion is the wave period, presenting an almost linear trend with the increment in sediment transport.

The study shows that an increase in peak period of $25 \%$ generates an increase in sediment transport of $18 \%$ at location. No clear trend has been found in the peak period variations during the past 70 years, i.e. no change from the past; this parameter has the potential to further influence erosion at the location.
- The influence of the wave attack angle was studied numerically with the variation of coast alignment. The sector $\left[250^{\circ}\right.$ $\left.295^{\circ}\right]$ is stable around $270^{\circ}$, while within sector $\left[340^{\circ}-25^{\circ}\right]$ most of the waves concentrate in between $0^{\circ}$ and $25^{\circ}$, with a large dispersion within and both summer and winter modes tend to shift from $20^{\circ}$ to $5^{\circ}$ during the studied period.

A shift towards north, as it was measured based on wave records, implies a larger relative angle in between coastline and mean wave direction, and therefore a smaller transport. Thus, this shift in direction attenuates the sediment transport so the wave attack angle currently mitigates erosion effects at Nørlev Strand.

- Increasing depths in the offshore contours of the beach allows for larger wave heights to approximate the coastline.

It is estimated that for an increment of water level of $25 \%$ we have an increase of sediment transport of circa 2-3\%. This, added to an increasing trend in the sea level rise, would lead to more pronounced and more frequent wave attacks to the beach dunes and to the houses protected by those dunes. The increasing depth has a potential to worsen costal erosion at the location with the trends presented in this study.

- The other parameters considered (gran size and seabed roughness) have a secondary influence on the sediment transport. The event duration seems to be an important parameter with a linear relation between increment in duration and increment in sediment transport, but further analysis is necessary in order to obtain a reliable description.

Finally, it is concluded that in a coastline like the one under examination, the accumulated precipitation (which is also increasing under the effect of climate change as 200 years national records suggest) must be of relevance in the stability of the sand dunes and sand cliffs. Future work should be conducted to quantify and model the influence of this parameter on beach erosion and sediment transport.

\section{Appendix 1}

\section{Effective Shields parameter}

This procedure is obtained from Liu 1999. The expression of the effective Shields' parameter is as follows:

$\theta^{t}=\frac{\tau_{w, \max }}{\rho \cdot\left(s^{-1}\right) \cdot g \cdot d}$

The results depends on the maximum shear stress in the bottom generated by the water particles, $\tau_{w, \max }$, the gravity 
acceleration constant, $g$, the particle diameter, $d$, the water density, $\rho$ and the relative density of the particle $s$, which in this case is sand.

The expression for the maximum shear stress in the bottom is:

$\tau_{w, \max }=\frac{1}{2} \rho \cdot f_{m} \cdot U_{m}^{2}$

which depends on the wave friction factor, $\mathrm{f}_{\mathrm{w}}$ :

$f_{w}=\exp \left(5.5 \cdot\left(\frac{\kappa_{S}}{A}\right)^{0.2}-6.3\right)$

and the horizontal particle velocity in the bottom, $U_{m}$ :

$U_{m}=A \cdot \omega=A \cdot \frac{2 \pi}{T}$

From these two expressions it is still necessary to define $\kappa_{s}$, which is the bed roughness. When calculating the effective Shields parameter, it is imposed Eq. (A.5)

$\kappa_{s}=2.5 \cdot D_{50}$

$D_{50}$ is $0.233 \mathrm{~mm}$.

Another unknown parameter is $A$, which is defined as the amplitude of the oscillation of the water particle on the sea bed:

$A=\frac{H}{2} \cdot \frac{1}{\sinh \left(\frac{2 \pi h}{L}\right)}$

$A$ is used in expressions (A.4) and (A.3).).

Finally, $L$ is the wave length, calculated by iteration and by applying linear wave theory:

$L=\frac{g \cdot T^{2}}{2 \pi} \cdot \tanh \left(\frac{2 \pi h}{L}\right)$

The effective Shields parameter is used to calculate Nikuradse's bed roughness, which is an important calibration parameter.

Open Access This article is licensed under a Creative Commons Attribution 4.0 International License, which permits use, sharing, adaptation, distribution and reproduction in any medium or format, as long as you give appropriate credit to the original author(s) and the source, provide a link to the Creative Commons licence, and indicate if changes were made. The images or other third party material in this article are included in the article's Creative Commons licence, unless indicated otherwise in a credit line to the material. If material is not included in the article's Creative Commons licence and your intended use is not permitted by statutory regulation or exceeds the permitted use, you will need to obtain permission directly from the copyright holder. To view a copy of this licence, visit http://creativecommons.org/licenses/by/4.0/.

\section{References}

Ahrens JP (2000) A fall-velocity equation. J Waterw Port Coast Ocean Eng 126(2):99-102

Andersen TL. Wind generated waves I (2016). Department of Civil Engineering, Aalborg Universitet, 2016

Andersen TL, Frigaard P, Burcharth HF (2014) Lecture notes for the course in water wave mechanics, Department of Civil Engineering, Aalborg University

Badulin SI (2014) A physical model of sea wave period from altimeter data. J Geophys Res Oceans 119(2):856-869

Baptista P, Coelho C, Pereira C, Bernardes C, Veloso-Gomes F (2014) Beach morphology and shoreline evolution: monitoring and modelling medium-term responses (Portuguese NW coast study site). Coast Eng 84:23-37

Bryant EA (1985) Rainfall and beach erosion relationships, Stanwell Park, Australia, 1895-1980: worldwide implications for coastal erosion, Zeitschrift für Geomorphologie N.F. Supplement 57:51-65

Davidson-Arnott RG, Pollard WH (1980) Wave climate and potential longshore sediment transport patterns, Nottawasaga Bay, Ontario. J Great Lakes Res 6(1):54-67

De Nationale Geologiske Undersøgelser for Denmark og Grønland (2017). URL http://www.geus.dk/.Online. Accessed 2018-08-06

Dean RG (2003) Beach nourishment: theory and practice (Vol. 18). World scientific publishing company

DHI (2016) Littoral Processes FM

Graeme S (2011) Storminess in a warming world. Nature climate change. Nat Publ Group 1:252-253 https://www.nature.com/articles/ nclimate1176

Hwang PA, Teague WJ, Jacobs GA, Wang DW (1998) A statistical comparison of wind speed, wave height, and wave period derived from satellite altimeters and ocean buoys in the Gulf of Mexico region. J Geophys Res Oceans 103(C5):10451-10468

Jenkins GJ, Perry MC, Prior MJO (2008) The climate of the United Kingdom and recent trends. Met Office Hadley Centre, Exeter

Li F, van Gelder PHAJM, Vrijling JK, Callaghan DP, Jongejan RB, Ranasinghe R (2014) Probabilistic estimation of coastal dune erosion and recession by statistical simulation of storm events. Appl Ocean Res 47:53-62

Liu Z (1999) Sediment transport, Aalborg Universitet

Liu Z, Frigaard P (1999) Generation and analysis of random waves, Aalborg Universitet

Medina R, Losada MA, Losada IJ, Vidal C (1994) Temporal and spatial relationship between sediment grain size and beach profile. Mar Geol 118(3-4):195-206

Morton ID, Bowers J (1996) Extreme value analysis in a multivariate offshore environment. Appl Ocean Res 18(6):303-317

Saye SE, Pye K (2006) Variations in chemical composition and particle size of dune sediments along the west coast of Jutland, Denmark. Sediment Geol 183(3-4):217-242

Silva FG, de Oliveira Sousa PHG, Siegle E (2016) Longshore transport gradients and erosion processes along the Ilha Comprida (Brazil) beach system. Ocean Dyn 66(6-7):853-865

USACE (2002) US Army Corps of Engineers. Coastal engineering manual Engineer Manual, 1110, 2-1100, 2002

van Gent MRA, de Vries JVT, Coeveld EM, De Vroeg JH, van de Graaff J (2008) Large-scale dune erosion tests to study the influence of wave periods. Coast Eng 55(12):1041-1051

Wang P, Davis RA, Kraus NC (1998) Cross-shore distribution of sediment texture under breaking waves along low-wave-energy coasts. J Sediment Res 68(3):497-506

Publisher's note Springer Nature remains neutral with regard to jurisdictional claims in published maps and institutional affiliations. 